\title{
Filmidest inspireeritud laste ja noorte mängud 1950. aastate Eestis
}

\author{
ASTRID TUISK
}

Minu kinoskäigud algasid saksa ajal. Käis sõda. Ärevuse ja mure tasakaalustamiseks oli

vaja midagi ilusat, rahustavat. Mängukaaslase ema käis kirikus. Minu ema kinos. [---] Nõukogude ajal ema õmbles laua taga palju. Sai harva kinos käia. Siis oli nii, et keset tuba kareldes tuli film talle võimalikult ilmekalt ette mängida. (EKM ERA, DK 638, 24-25 < Tartu l < Viljandi l - K. H., snd 1938 (2019))

\section{Meedia laste mängude eeskuju ja suunajana}

Lapsed kaasavad oma mängudesse meedias nähtud tegelasi, süžeesid ja teemasid. Mitmed stsenaariumid jõuavad laste mängudesse nende endi igapäevaelu tähelepanekute kaudu, eeskuju võetakse lastele tuttavast keskkonnast, päriselust. Lapsed korjavad ja miksivad tegelaskujusid, ideid ja teemasid ka teistest allikatest, sealhulgas eakaaslastelt ja meediakanalitest. Meedia mõju ei piirdu ainult televisiooniga, enne televisiooni tulekut võidi oma mäng kujundada raadiost kuuldu või raamatust loetu põhjal, veel varasemal ajal aga täiskasvanute juttude järgi (Kalliala 2006: 52; Opie, Opie 1984: 12, 330). Meedia osa laste mängukultuuri mõjutamisel tõstavad esile mitmed uurijad. On tehtud kindlaks, et üha rohkem on mängustsenaariumid eemaldunud päriselust, varem saadi enamik kujutlusmängude rollidest ja ideaalidest vahetust eluringist (Vissel 2004: 187; Korkiakangas 1996: 75; Kalliala 2006: 72-73). 2000. aastate alguses kujutasid eesti lasteaialapsed oma loovmängudes sageli hiljuti nähtud telesaadete tegelasi: teletupse, Batmani, Pipit jt (Veidenbaum 2003). Tänapäeval võtavad lapsed oma mängudesse ideid erinevatest internetiallikatest, näiteks arvutimängudest ja mobiilirakendustest (ehk äppidest) (Marsh jt 2018).

Lastemängude ja meedia uurijad ei poolda arusaama, et lapsed on vaid passiivsed kõrvaltvaatajad, kellele meediast nähtu ühepoolselt mõju avaldab (Tucker 2008: 111; Kalliala 2006: 52). Ka sotsioloogid räägivad lastest kui aktiivsetest oma tahte, huvide ja soovidega sotsiaalsetest tegutsejatest. Lapsed loovad oma unikaalset eakaaslaste kultuuri, kasutades selleks innovatiivselt ja loominguliselt ka täiskasvanutemaailma mõjutusi. Lapsed ise on aktiivsed osalejad mõlemas kultuuris (Corsaro 2005). Kate Willett nimetab meediast innustust saanud mänge remiksideks, kus lapsed eri algupäraseid aineid kokku segavad ja enda erinevatele kultuurilistele teadmistele, oskustele ja soovidele tuginedes mängudes uuesti esitavad. Ta tõstab esile laste osa selles protsessis, öeldes, et lapsed loovad niimoodi oma remiksitud kultuuris uusi tähendusvälju (Willett 2014: 149). 
Meedia mõju ei ole neutraalne, see on ideoloogiliselt laetud. Meedial nähakse tõhusat osa laste sotsialiseerimisel, seda eriti tänapäeval, mil ekraanimeedia kulutab üha rohkem aega. Andra Siibak ja Kristi Vinter on välja toonud, et paljud lapsed kujundavad „arusaama iseendast meedia kaasabil. Meedialemmikute toel proovitakse uusi rolle, konstrueeritakse identiteete ning kujundatakse sotsiaalseid suhteid teiste lastega. Muuhulgas peetakse meediat laste sugupoolt puudutavate rollide ja arusaamade mõjusaks kujundajaks." (Siibak, Vinter 2014: 85)

Fantaasiamänge on peetud täiskasvanuea rollide otseseks ettevalmistuseks. Mängides ja mängude kaudu õpivad lapsed ka soorolle ja rollikäitumist (Shuffelton 2009: 225; Tucker 2008: 108-112). Nii toimivad mängud sotsialiseerimisvahendina, mis aitab lastel õppida meestele ja naistele „sobivat” käitumist sellisel viisil, nagu neid määrab kultuuriline norm (Tucker 2008: 108-112).

Tänapäevase meedia roll ühiskonnas on oluliselt suurem, kui oli 1950. aastatel. Praegu veedavad lapsed ekraanimeedias rohkelt aega. Otseselt neile on suunatud nii üks osa meediatoodetest kui ka mänguasjatööstusest, kus meedias nähtud tegelasi mänguasjadena turule tuuakse (Lindstrom, Seybold 2004). Üks suur erinevus kahe lastepõlvkonna vahel ongi selles, et kui XXI sajandil tarbivad kõik meediat (ka lasteaia- ja kooliealised lapsed), siis varem oli meedia eksklusiivne ja mitte nii kergesti kättesaadav (Süss 2007: 783). Aga 1950. aastatel sai kinoskäimine lastele võimalikuks ja seda kasutati palju.

\section{Allikad ja uurimisküsimused}

Artikli motoks valitud katkend iseloomustab kõnekalt kino olulisust sõjaaegsete laste ja nende vanemate jaoks. Isegi sedavõrd, et kinos nähtud lugusid etendati ja elati veel kord mängides läbi. Selles artiklis vaatlengi mälestuste põhjal kino mõjutusi lastekultuurile, Eesti laste 1950. aastate filmidest inspireeritud mänge. Jutt käib ainult kino mõjutustest, sest Eesti Televisioon alustas ülekandeid küll 1955. aastal, kuid esialgu polnud paljudel peredel televiisoreid. Oma kogemustele tuginevates erinevates tekstides jutustatakse filmidest inspiratsiooni saanud mängude mängimisest. Pajatatakse ka Nõukogude sõjafilmidest, kuid meenutajatele meeldisid pigem välismaa filmid, mis ei rääkinud sõjast ja võitlusest, näiteks 1940. aastate lõpus kinodesse jõudnud välis- ehk trofeefilmid.

Allikana kasutan Eesti Kirjandusmuuseumi Eesti Rahvaluule Arhiivi lastemängude kogumisvõistlusele laekunud kaastöid. Võistlusel osales 45 eri vanuses inimest. Kaastöödes ei kirjeldata ainult oma lapsepõlve tegevusi, vaid seletatakse neid ka lahti, avatakse taustu ja arutletakse nende üle. Eraldi küsimust filmide ja neist lähtuvate mängude kohta juhendis ei olnud, küll küsiti kujutlus- ehk fantaasiamängude kohta, mida ise välja mõeldi. Samuti toetun elulugude ja rahvaluule teemadel kirjutajate ringi kümnele kaastööle. Tegemist on kord kuus kokku saava rühmaga, kus kodus kirjutatakse ja rühmas loetakse ette 1-2 lehekülje pikkune tekst. ${ }^{1}$ Vaat-

\footnotetext{
${ }^{1}$ Elulookirjutajate rühmast vt Kirss, Hinrikus 2010. 2019. aastal kujunes sarnane rühm ka rahvaluule arhiivi Tartu piirkonna kaastöölistest.
} 
len lugusid teemal „Kino minu elus”. Meenutajate sünniaastad jäävad vahemikku 1929-1952. Mitmed kirjutajad on rahvaluule arhiivi kaastöölised või pikaaegsed elulooringi liikmed. 1950. aastatel üleskasvanud kirjutajad on praeguseks pensionieas, kuid tegusad inimesed.

Tegemist on tekstidega, mis on kirjutatud spetsiaalselt võistluste või kokkusaamiste jaoks ja põhinevad kirjutajate endi kogemustel. Folkloristikas on selliseid, just kogumisvõistlustele saadetud kaastöid nimetatud teemajutustusteks või teemakirjutusteks (Jaago 2018: 6; Pöysä 2009: 41). Eesti Rahvaluule Arhiivis on viimastel aastatel korraldatud mitmeid (isikukeskseid) teemakogumisi, sellisest viisist on saanud tavapärane arhiiviainese loomistava. Samas ei ole kogumisvõistluste tulemusi, teemakirjutusi, Eestis märkimisväärselt analüüsitud.

Lapsepõlve kinoskäigu, filmielamuste ja filmidest inspiratsiooni saanud mängude kirjeldamine moodustab ühe osa lapsepõlvemälestustest. Kuna siinsed teemakirjutused on tekkinud vanemate inimeste lapsepõlvemeenutustest, tuleb nende analüüsimisel arvestada mäletamise ja minevikulise vaatenurgaga seotud aspekte. Meenutuste kirjutamine on alati valikuline ja hinnanguline. Mälestusi võidakse elu jooksul ümber hinnata, neid mõjutavad hilisemad kollektiivse ja individuaalse ajaga seotud sündmused. Meenutuste kirjutamine on nii praeguse kui ka tulevase läbitöötamine mineviku kaudu, kus minevikule antakse tähendusi oleviku vaatepunktist (Kõresaar 2005; Portelli 2006: 55).

Ka mängudest lähtudes ei saa rääkida nende täpsetest kirjeldustest, vaid mälestustest nende kohta. Mitmed mängud pole enam meeles, kuid seda enam on põhjust peatuda mängudel ja mänguviisidel, mis korduvad mitme kirjutaja töödes. Üheks selliseks ongi kinos nähtud filmidest inspiratsiooni saanud mängud ja muud tegevused, mida juba pensionieas kirjutajad meenutavad.

Minevikust jutustamiseks on mitmeid viise, aga selle fookuse valib alati kirjutaja. Arvatavasti mõjutas just biograafiline aeg (lapsepõlveaeg) ja kogumisviis seda, et oma mängukogemust ei asetata laiemasse ajaloolisse ja sotsiaalsesse konteksti, kuna juhendites ei ole seda palutud teha. Valitud on lapse vaatepunkt. Mänge vahendatakse võimalikult tolleaegse lapse seisukohalt, laiemaid teadmisi ajaloolistest ja poliitilistest oludest jagatakse kujutletavatele lugejatele vähesel määral. Vahel võidakse samastada end mingite rühmadega ning rääkida kogu rühma, näiteks põlvkonna nimel.

Teemakirjutusena saadetud kaastööde põhjal on mõttekas avada just kirjutajate suhtumisi ja vaateid. Põlvkonna ühtset minevikupilti ning ajaloolist tõde pole nende abil kerge kindlaks teha (Pöysä 2009: 51-52). Pöörangi tähelepanu sellele, mida kirjutajad oma kaastöödes on soovinud edasi anda. Et saada uurijana aru 1950. aastate mängukogemustest, avan tollast ajaloolist ning kultuurilist konteksti. Uurimismeetodina kasutan kontekstualiseerimist (Bauman, Briggs 1990: 66-72). 


\section{Ajalooline taust}

1950. aastate Eesti oli okupeeritud, äsja oli lõppenud Teine maailmasõda. Hilisstalinistlikul perioodil (1944-1953) algas laiaulatuslik ühiskonnaelu sovetiseerimine. Ühiskonnas tugevnes ideoloogiline surve. Lammutati senine majandussüsteem, kehtima hakkas käsumajandus, muuhulgas moodustati kolhoosid, kollektiviseerimine laostas suure osa maaelanikkonnast. Stalinliku režiimi repressioonid tipnesid 1949. aasta märtsiküüditamisega. Sõjajärgne aastakümme oli metsavendluse kõrgperiood. Ulatuslik venekeelse elanikkonna migratsioon muutis Eesti rahvuslik-demograafilist struktuuri. Valitses nii toidu- kui ka tarbekaupade puudus, rasketööstuse eelisarendamise tõttu oli tugevalt häiritud laiatarbekaupade tootmine ja inimeste igapäevaelu vajaduste rahuldamine (Pajur, Tannberg 2005:271-288). Raskesti kättesaadavad olid peaaegu kõik vajalikud kaubad: toiduained, tarbeesemed, tööriistad, riided, mööbel jms. Toidulaud oli kesine (Kannike, Vahtre 2018: 70-80).

Ühiskonnas tugevnes ideoloogiline surutis. Kirjanduses ja kunstis oli nõutav Nõukogude ühiskonna lakeeritud käsitlemine ja ülistamine, mõõdutundetult juurutati juhikultust. Jossif Stalin sai keskseks tegelaseks kirjandusteostes, kunstis, kinolinal ja teatrilaval (Pajur, Tannberg 2005: 272). Avalikud infokanalid olid suurel määral rakendatud kommunistliku ajupesu teenistusse, seega saatis nõukogude inimest kõikjal propagandafoon (Kannike, Vahtre 2018: 84-85).

\section{Nõukogude kino 1950. aastatel}

Eesti esimene paikkino avati Tartus 1908. aastal, kinomaju ehitati suurematesse linnadesse. Pärast Teist maailmasõda hakkasid Nõukogude Liidus, k.a Eestis, tegutsema nn rändkinod. ${ }^{2}$ Rändkino seansid toimusid rahvamajades, koolimajades, kolhoosikeskustes, aga ka vabas õhus. Huvi oli suur, kuna kino oli enne televisiooni tähtsaim visuaalne meedium, kuid oli ka „aknaks läände” (Mertelsmann 2012: 151). Kinoseansid olid külanoorte sotsiaalse suhtluse kohaks, sest sõjajärgsetel kümnenditel järgnes filmivaatamisele tavaliselt tantsuõhtu. Filmide näitamise korraldamisega tegeldi riiklikult, pikka aega tegi seda ENSV Riiklik Kinokomitee. Rangelt oli kindlaks määratud, mida tohib näidata; filmidele, ka trofeefilmidele, eelnes propagandistlik nõukogude elu tutvustav ringvaade. Ehkki otseselt lastele ja noortele mõeldud filme oli näidatavate hulgas tollal vähe, moodustasid just nemad suure ja vastuvõtliku vaatajate grupi.

Nõukogude riik (eeskätt Jossif Stalin) oli võtnud suuna kogu maa kinofitseerimisele, samas loodeti kinode abil täita ka riigikassat. Nõukogude Liidu filmitoodang oli sel ajal vähene. Nii hakati kinodes näitama ka välis- ehk trofeefilme. Nimelt leiti Saksamaalt Reichsfilmarchivist, mis 1945. aastal pärast Saksamaa kaotust Nõu-

\footnotetext{
${ }^{2}$ Rändkino on filmide plaanipärase näitamisega (selleks kavandatud või ka juhuslikes ruumides, samuti vabas looduses) tegelev rändüksus. 1960. aastal oli Nõukogude Liidus 27890 ja Eestis 197 rändkino (ENE 1975: 16). Peale rändkino tegutsesid Eestis ka paikkinod, 1950. aastal loetleti Eestis 207 kohta, kus näidati kino (Mertelsmann 2011: 64).
} 
kogude tsooni jäi, 17000 mängufilmi. Osa trofeefilme tiražeeriti, dubleeriti ja need linastusid Nõukogude Liidus aastatel 1947-1956, mitteametlikult näidati neid ka hiljem (Kanter 2014; Kenez 2009: 191-195; Mertelsmann 2012: 149-151).

Trofeefilmidele heideti ette ideoloogilist sobimatust nõukogude inimestele, ka prooviti nende näitamist ära keelata ja suunata, see aga ei õnnestunud (Kanter 2014; Kenez 2009: 193). Trofeefilmid said kogu Nõukogude Liidus väga populaarseks, kujunedes lausa kultuurifenomeniks ning mõjudes kultuurišokina (Mertelsmann 2011: 65, 2012: 150; Tanis 2017). Inimesed olid filmidest lummatud, väljendades seda erinevalt, nende linastumisel toimus segadusi. ${ }^{3}$ Näitlejannadest, näiteks Marika Rökkist, sai Nõukogude Liidus kogu põlvkonna naiselik eeskuju (Tanis 2017). Menu üheks põhjuseks oli see, et trofeefilmid erinesid oluliselt Nõukogude filmidest. Need olid peamiselt Ameerika, aga ka Saksa muusika-, komöödia- ja seiklusfilmid. Ühelt poolt esindasid need „akent teise maailma” ja teistsugust elustiili, teisest küljest ei puudutanud igapäevateemasid, vaid olid omamoodi "eskapistlikud muinasjutud”. Nad erinesid oluliselt Nõukogude filmikunstis valitsenud sotsialistlikust realismist (Mertelsmann 2011: 67-68). ${ }^{4}$

Valmis said ka esimesed sõjajärgsed eesti näitlejatega tehtud filmid „Elu tsitadellis” (1947) ja „Valgus Koordis” (1951), mis samuti meeldisid inimestele.

Nõukogude filmid olid propagandavahendiks, mille kaudu juurutati nõukogude võimu ideoloogilisi põhimõtteid. Muuhulgas oli ideoloogilises kasvatustöös tähtis osa kangelase ja vaenlase kuvandil. Sõjajärgsetel aastatel oli vaenlaseks number üks fašism, millele vastandati nõukogude patriotism. Laste- ja noortefilmides, aga ka raamatutes ning raadiosaadetes näidati noorte kangelaste võitlust kodumaa eest (Raudsepp, Veski 2015: 209-210).

Nii erinesid trofeefilmid Nõukogude filmidest nii teemadelt kui ka kujutusviisidelt. Teistsugune oli kogu olustik, moodustades kontrasti eriti laste ja noorte jaoks, kes olid sündinud ja üles kasvanud sõjajärgsete aastate tegelikkuses, majanduslikult viletsas keskkonnas. Märgatavalt erines trofee- ja nõukogude (sõja)filmide armastus- ja romantikateema käsitlemine. Nõukogude filmides oli ka armastus allutatud ideoloogiale, armastada sai vaid õigel teel olevat nõukogude kodanikku. Romantiline liin oli nõrk ja vaoshoitud, tunnete kujutamine kitsapiiriline (Borissova 2008). Välismaa filmides esitleti armastust kui tõelist, suurt ja ennastohverdavat tunnet. 1950. aastate keskpaigast, kuid eriti järgnevatel aastakümnetel, kujundasid nii nõukogude inimeste kui ka toonaste laste arusaamist romantilistest suhetest ja käitumisest ka India ja Argentiina armastusfilmid (Borissov 2002: 290; Kalmre 2015a: 1333; Rupprecht 2017: 85-87).

\footnotetext{
${ }^{3}$ „1947. aasta kevadet, Marika Rökki, aga eelkõige „Minu unistuste naise” (1944) ekraanidele tulekut Moskvas mäletati aastaid - järjekordadest spekulatsioonideni piletitega, mida polnud eales varem nähtud” (Kanter 2014: 126). Tbilisist meenutab Bulat Okudžava: „Normaalne elu linnas katkes. Kõik rääkisid filmist ning ruttasid seda vaatama, kui neil vähegi oli selleks võimalus. Inimesed vilistasid tänavatel filmilaulude meloodiaid, poikvel akendest kostus, kuidas klaveril laulukesi mängiti." (Kenez 2009: 192-193)

${ }^{4}$ Lõbusama osa nõukogulikust kinokunstist moodustasid 1930. aastatel valminud ülimenukad Nõukogude muusikalised komöödiad Ljubov Orlovaga peaosas: „Lõbusad semud”, „Volga, Volga”, „Tsirkus” (Mertelsmann 2011: 67-68).
} 


\section{Mängutegelikkus 1950. aastatel}

Kasvamine ja mängimine sõjajärgsetel aastatel paistab silma mitmete erijoonte poolest. Kuigi lastel oli arvestatav töökoormus, leidsid nad ikkagi aega mängimiseks. Mänguvahendite nappust, nende ise valmistamist looduslikest ja teistest kättesaadavatest vahenditest märgitakse Teise maailmasõja ja sellele järgnenud aja lastemängude uurimustes (Paksuniemi jt 2015; vt ka Tuisk 2019: 66). Suur oli ka õuemängude osakaal, kambas tegutsemine andis lastele õlg-õla tunnet.

Mitmes uurimuses vaadeldakse ka seda, kuidas sõjaaja keskkonna ja oludega kohanetakse just mängude ja mänguliste situatsioonide kaudu. Mängudes olukordi ja situatsioone endale sobivas suunas juhtides, näiteks varemetes mängides ja sõjamoona mänguks kasutades, luuakse oma mõtetes justkui kontroll kohtade, asjade ja situatsioonide üle. Nii saadakse hakkama sõjaaja hirmutavas ning vaenulikus keskkonnas (Moshenska 2019: 153-154; Paksuniemi jt 2015; Rõblova, Nazarova 2014). Sõjamoonaga mängimine jätkus sõjajärgsel ajal: laste mänguvahenditeks said sõjategevusest maastikule jäänud padrunid, mürsukestad, aga ka laskeriistad ja sõjatehnika tükid (Tuisk 2018).

Erinevate maade uurijate, aga ka lastemängude võistlustöödes tõstetakse esile Teise maailmasõja ajal ja pärast seda valitsenud sõjamängude rohkust. Ideid mängudeks saadi päriselust: näiteks mängiti küüditamist, tagaajamist, kus põgenejateks olid vangid, aga ka kolhoosikoosolekut ja -pulmi. Sõjamängudeks võidi ideid saada ka filmidest.

Ometi ei ole neis minu vaadeldavates meenutustes Pavlik Morozovi ega teiste nõukogude lapskangelaste imiteerimist. Pigem jäljendati filme, mis ei olnud nii üleideologiseeritud ja vägivaldsed, kus süžeed olid seikluslikud, näiteks „Timurit ja tema meeskonda,", nagu kirjeldab 1952. aastal sündinud naine. Võrdluseks, XX sajandi keskpaiga Nõukogude lastefilmides oli esikohal ideoloogiline võitlus ja tegelased selgelt polariseeritud. Peale „vaenlaste” võideldi lastefilmides mitteustavate ja ennasttäis kaaslaste vastu, kes vahel filmi käigus ka ümber kasvasid (Fjodorov jt 2017). Järgmisel kümnendil ilmusid laste mängurepertuaari uue rolli- ja seiklusmängude teemana „Valged ja punased roosid”: esimene Astrid Lingdreni „Meisterdetektiiv Kalle Blomkvisti” sarja raamat ilmus eesti keeles 1960. aastal.

\section{Meenutajate vaade: sõjafilmid, trofeefilmid ja nendest inspiratsiooni saanud mängud}

Kinoteemalistes lugudes kirjeldatakse seda, missugust emotsionaalset mõju kino ja filmid lastele või juba neidudele-noormeestele avaldasid. Lisaks sellele, et meeles on filmi süžee, jutustatakse ka sellest, mis juhtus enne kinoskäiku, mida filmi vaadates tunti jne. Tähenduslik ning nende olulisust näitav on asjaolu, et nii mänge kui

\footnotetext{
${ }^{5}$ Film „Timur ja tema meeskond” linastus 1940. aastal, eesti keelde dubleeriti see 1945. aastal. Arkadi Gaidari raamat ilmus eesti keeles 1945, raadiokuuldemäng valmis 1952. aastal.
} 
ka muid filmidest inspiratsiooni saanud tegevusi mäletatakse praegugi, olles juba vanemas eas. Eriline koht meenutustes on sõja- ja trofeefilmidel, mida mälestustes omavahel ka vastandatakse.

Lastele mõjus tugevalt sõjafilmides nähtu. Nii näiteks jutustab Muhus koolis käinud naine sellest, kuidas lapsed pärast filmi „Noor kaardivägi”6 nägemist seda õues nii suure kirega mängima asusid, et õpetajad mängu ära keelasid (EKM ERA, DK 124, 1-10 < Tallinna $1<$ Muhu khk - M. L., snd 1940 (2013)). Selles filmis käsitletakse Saksa okupatsiooni aegset noorte vastupanuliikumist, sündmused on traagilised ning film pole noorematele lastele eakohane. Filmis on ka romantiline liin, nagu enamasti Nõukogude sõjafilmides.

Mitmed oma lapsepõlve kinoelamustest kirjutajad tõstavad esile, kuidas sõjafilmid neis hirmu tekitasid. 1929. aastal sündinud mehele jättis filmi „Noor kaardivägi” kohustuslik vaatamine tugeva halvava jälje: „See film muserdas mu psüühikat nii koledasti, et ma ei läinud enam kinno vist mitu aastat" (EKM EFA I 316, 55-56 $<$ Kambja khk < Tallinna l - K. K., snd 1929 (2019)). Samasuguseid heidutavaid elamusi võisid lastele tekitada ka pealtnähtud või liiga julmaks keeranud sõjamängud, nagu mitmes mälestuses välja tuuakse.

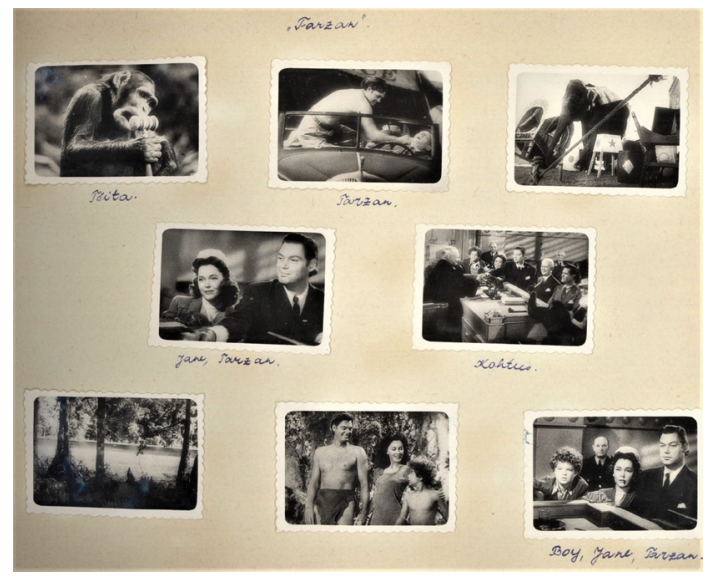

Lehekülg M. P. (snd 1938) 1953-1957 Viljandi kultuurikoolis peetud filminäitlejate pildiallbumist.

Üheks filmiks, millest meenutustes juttu tehakse, on „Tarzan”7 Seda meenutatakse nii lastemängude võistlustöödes, kus kirjutamisel on lähtutud just mängudest,

\footnotetext{
${ }^{6}$ Filmi „Noor kaardivägi” (1948) lavastas Mosfilmis režissöör Sergei Gerassimov. Film on valminud Aleksander Fadejevi samanimelise romaani (1947) ainetel. Aleksander Fadejev oli stalinistliku ideoloogia ja poliitika olulisemaid elluviijaid kirjanduses.

${ }^{7}$ Esimene Tarzani-jutustustel põhinev film valmis 1918. aastal. Filmikompanii Metro-GoldwynMayeri esimene suure populaarsuse saavutanud film „Ahvide Tarzan” linastus 1932. aastal, selle peaosades mängisid Johnny Weissmüller ja Maureen O'Sullivan. Filmile järgnes veel mitmeid osi ja need levisid üle kogu maailma. Film põhineb Ameerika kirjaniku Edgar Rice Burroughsi 1910. aastatel ilmunud jutustustel. Mitmed Burroughsi Tarzani elust pajatavad jutustused ilmusid alates 1923. aastast ka eestikeelsena. 1950. aastatel üleskasvanud lapsed võisid nende raamatutega tuttavad olla.
} 
kui ka kinoteemalistes lugudes. Tarzani-seeria filmid (1932, 1934, 1936) jooksid Eesti kinodes juba 1930. aastail. Oma filmivaatamist ja Tarzani-mängu meenutab Lõuna-Eesti väikeses külas üles kasvanud naine, mängu mängimisest teevad juttu veel kolm naist:

Väga populaarne oli „Tarzan”, peaosas Johnny Weissmüller ja Jane Maureen O'Sullivan. Tagulas tuli selline rahvamurd kokku, et kõik ei mahtunud saali. Meie ronisime aknast sisse ja istusime põrandal, meeter ekraanist. Oli maikuu. Poisid õppisid pärast seda kooli õues Tarzani häält tegema ja sidusid köied puude okste külge, et nende otsas nagu liaanidega kiikuda. Siis otsiti veel Jane’i, keda puu otsa tõsta - mina olin meie klassist kõige väiksem ja kergem. (EKM ERA, DK 632, 16-17 $<$ Kuressaare l < Sangaste khk - M. P., snd 1938 (2019))

Trofeefilmide mõju tüdrukutele (või juba neidudele) tõstab esile meenutaja, kes otsesõnu vastandab nii Nõukogude sõjafilmide kangelasi teiste filminäitlejatega kui ka sõjateemasid välismaa filmide armastusteemadega. Lõigu lõpus ta avaldab, et oli ühesse näitlejasse lausa armunud:

Mul oli kõriauguni nõukogude propaganda poolt kangelasteks tehtud tegelastest. Jälle Pavel Kortšagin, Pavlik Morozov, Zoja Kosmodemjanskaja, Volodja Dubinin. Pidime neid klassist klassi ikka jälle kordama, pähe õppima tekstikatkeid. Mõni katkend on mällu jäänud nagu issameie. Nüüd armusin uutesse kangelastesse, kellel polnud vähimatki sarnasust eelmistega. Nad ei lehvitanud punaseid lippe, neil ei olnud püsse seljas ega vähimatki tahtmist kuulipilduja torule viskuda. Nad olid kaunid ja edukad, julged ja ettevõtlikud tegelased. Ja neid mängisid suurepärased näitlejad. Minu lemmiknäitlejateks said Audrey Hepburn ja Rex Harrison filmist „Minu veetlev leedi". (EKM ERA, DK 633, 16-18 < Tartu l < Suure-Jaani khk - E. U., snd 1945 (2019))

Üks teema, mis naissoost kirjutajate kaastöödes esile kerkib, on näitlejate mängimine. 1930. aastatel sündinud naised jagavad oma muljeid sellest, kuidas nad näitlejannasid imiteerisid. Üks, keda nimetab mitu meenutajat, on lapsnäitleja Shirley Temple.

Kooliajal jooksid kinodes trofeefilmid õnnelike lõppude ja kuulsate näitlejatega: Zarah Leander, Deanna Durbin, Marika Rökk, Shirley Temple, Lilian Harvey, iluuisutaja Sonja Henie. Need filmid haarasid meid ilu, tantsu ja muusikaga. [---] Lõpuks hakkasime ise mängima neid filmitähti. Igaüks meist võttis omale ühe lemmiku nime ja „kehastus” selleks näitlejaks. Kõige paremini õnnestus mu pinginaabril, sest ta oli ise loomult väike, ilus, armas eputis nagu Shirley Temple. Kirjutasime kirju üksteisele kui tegutsevad filmitähed. Kooli tulles vahetasime neid. (EKM ERA, DK 638, 24-25 < Tartu l < Viljandi l. - K. H., snd 1938 (2019))

\footnotetext{
${ }^{8}$ „Minu veetlev leedi” on kaheksa Oscariga pärjatud 1964. aasta filmikohandus samanimelisest muusikalist. Filmi režissöör oli George Cukor, peaosades Audrey Hepburn ja Rex Harrison. http://www.filmiveeb.ee/filmid/2486/Minu-veetlev-leedi/
} 
Teine neidude harrastus, mis on seotud ka Tarzani filmiga, on näitlejate fotode kogumine, nende vahetamine ja albumitesse kleepimine (EKM EFA I 169, 111-122 < Valga 1 - T. K., snd 1940 (2013); EKM ERA, DK 638, 24-25 < Tartu l < Viljandi 1 - K. H., snd 1938 (2019)); EKM ERA, DK 632, 16-17 < Kuressaare l < Sangaste khk M. P., snd 1938 (2019)). Mälestusi sellelaadsest kogumistegevusest jagatakse ka elulugudes (EKM ERA, DK 387, 1-5 < Tartu 1 < Viru-Nigula khk < Hargla khk - V. S., snd 1946 (2017); Mertelsmann 2012: 151). Kogumisest kirjutab pikemalt seesama Tagula koolitüdruk, keda edasine elutee Viljandisse kooli viis. Tema filminäitlejate pildialbumis on kolm lehekülge pühendatud Tarzani filmile:"

Kõige suurem huvi filminäitlejate vastu ja eriti välismaa näitlejate vastu tekkis kogu meie toal ja minul endal ka aastail 1953-1957, kui õppisime Viljandi Pedagoogilises Koolis ja elasime kuuekesi samas toas Jakobsoni 32. Mingid koolipoisid tulid meile ühiselamusse fotosid pakkuma. Iga kord, kui film oli vaadatud, tulid nad oma fotodega. Oli meil raha nii vähe kui oli, aga me ei suutnud fotosid ostmata jätta. Vahel oli foto hind 2 rubla, vahel üks rubla tükk. Väga mitut filmi vaatasime kaks korda, kõik olenes näitlejatest nagu Eddy Nelson, Robert Taylor, Clark Gable, filmid „Tarzan”, „Saatuse kutse”. (EKM ERA, DK 632, 16-17 < Kuressaare l < Sangaste khk - M. P., snd 1938 (2019))

Nagu kirjeldustest selgub, lõigati näitlejate pilte välja ka ajalehtedes ilmunud kinoreklaamidest ning eestiaegsetest ajakirjadest. Fotosid kollektsioneeriti, neid vahetati omavahel. ${ }^{10}$ Üks meenutaja nimetab fotosid hindamatuks väärtuseks, mida siluti, koguni pesti ja triigiti (EKM ERA, DK 638, 24-25 < Tartu $1<$ Viljandi 1 K. H., snd 1938 (2019)). ${ }^{11}$

Oma lapsepõlve ühe tegevusena kajastatakse meenutustes pabernukkude meisterdamist, neile riiete joonistamist ja nendega mängimist. Ka seda tegevust on seotud filmi- ja teatrinäitlejate kujutamisega.

Kui arvestada vähest aega, mil trofeefilmid linastusid, on nendest tõukuvad mängud ja harrastused haaranud kirjutajate meenutustes tähelepanuväärselt suure osa.

\section{Tarzani film mängude ja harrastuste inspireerijana}

Tarzani filmi järgi mängimist käsitletakse ka mälestustel põhinevates ilukirjanduslikes teostes, näiteks Leelo Tungla „Seltsimees laps ja suured inimesed” (2008).

\footnotetext{
${ }^{9}$ Peale Tarzani filmi leidub albumis veel fotosid India filmidest, teistest Ameerikas toodetud trofeefilmidest ja näitlejatest, aga ka Nõukogude filminäitlejatest nagu Ljubov Orlova, Pavel Kadotšnikov jt; eesti- ja venekeelsete allkirjadega fotod Estonia teatri ooperitest „Jevgeni Onegin”, „Noor kaardivägi” ja näitlejatest (Elsa Maasik, Georg Ots jt).

${ }^{10}$ Eesti tüdrukute väljalõike- ja teiste albumite kohta vt Kalmre 2010. Sellest tegevusest 1950. aastatel Uus-Meremaal vt Sutton-Smith 1981: 218-220.

${ }^{11}$ Vaadeldavates meenutustes korratakse mitmel korral mõtet, et päris oma mänguasjad, aga ka näiteks raamatud, olid väga olulised, väärtustatud ja hoitud (Tuisk 2019: 59-60).
} 
Ülestähendusi neist mängudest on ka rahvaluulearhiivi kogudes, lastemängude uurija Anu Vissel on kirjutanud, et poisid aimasid juba 1930.-1940. aastatel järele filmi-Tarzanit (Vissel 2004: 188).

Tarzani filmide järelemängimine tuuakse näitena ära ka mitmes XX sajandi keskpaiga lastemänge käsitlevas uurimuses (Virtanen 1978: 29-30; Opie, Opie1984: 338; Chudacoff 2007: 130). Leea Virtanen esitab Tarzani-mängu sõjamängude peatükis, Peter ja Iona Opie paigutavad selle aga juturaamatute ja lugude maailma (Storybook World) põhinevate mängude hulka. Sinna kuuluvad erinevaid seiklusi imiteerivad mängud, aga ka „moodsad muinasjutud”, näiteks Tuhkatriinu-tüüpi vaeslaste või aaret otsivate seiklejate tegutsemised (Opie, Opie 1984: 337-338). Kirjeldused lasevad aimata, et mängus imiteeritakse Tarzani juhtumisi. Kuna lastele meeldib kujutada mängudes erinevaid seiklusi (Opie, Opie 1984: 332; Kalliala 2006: 73-82), siis selleks annab Tarzani film head eeskuju. Tarzani kirjeldamist osavana kohtab ka elulugudes. 2016. aastal kirjutatud eluloos kujutatakse samuti Tarzani mängimist. Episoodi kirjeldamist alustab kirjutaja puuokstega õhusõidust (EKM EKLA, f 350, m 1:2679).

Film tõi laste kasutusse uue teema seiklusliku fantaasiamängu jaoks. Fantaasia abil saab koolimaja õues, karjamaade ääres või mujal kasvavaid puid mõelda džungliks ja köisi kasutada liaanidena. Oma osavuse näitamine meeldib just poistele, millest tuleb juttu allpool. Nagu eespool märgitud, piiras laste mänguvõimalusi mänguvahendite nappus. Tarzani-mängu hea kohandumisena olemasolevasse keskkonda võib näha seda, et mänguks polnud vaja lisavahendeid: spetsiaalset riietust, selleks otstarbeks valmistatud mängukohti ega atribuutikat. Üheks ajastu tunnusjooneks nimetavad meenutajad vanemate suurt tööga hõivatust ja vähest tähelepanu lastele. Kohati see meeldis lastele, nagu kirjutajad samuti välja toovad. Laste lemmikkohad on sellised, kus puudub otsene täiskasvanute kontroll ja järelevalve: tänavad, tühermaad, aga ka puud, mille varjus saab mängida või mille otsa ronida (Opie, Opie 1984: 14-16; Tucker 2008: 112).

Poistele aga võis meeldida ka Tarzani tegelaskuju ise. Enamik lastemängude uurijatest tõdeb, et poiste ja tüdrukute lemmikkujutlusmängud, samuti nende kujutatavad lemmikkangelased, on erinevad (Evaldsson 2009: 323; Hughes 1993). Üldiselt on mängude uuringud näidanud, kuidas poisid eelistavad näidata oma füüsilist osavust, julgust ja sitkust, võitlusvaimu ja agressiooni, seevastu tüdrukute osaluskultuuris on tähtsal kohal omavaheline koostöö, lähedased suhted, verbaalsus ja leplikkus. Ann-Carita Evaldsson (2009: 316-328) toob küll oma lastemängude ja mängimise ülevaates mitmeid näiteid eel- ja põhikooliealiste laste soorollide konstrueerimisest ja avaldumisest mängimise käigus, kuid kriipsutab alla, et vastavate jäikade järeldustega tuleks siiski olla ettevaatlik. Nii poisid kui ka tüdrukud ópivad, katsetavad ja panevad proovile ning lükkavad ümber stereotüüpseid soorolle ning konstrueerivad mängulises suhtluses kattuvaid sotsiaalseid identiteete.

Ka filmi-Tarzani tegelaskuju lahates tuuakse esile tema maskuliinseid jooni. Teatavasti on Tarzan väljamõeldud tegelane, valge inglane, kelle Aafrika metsikus džunglis kasvatasid üles ahvid. Tarzanis on ühendatud karm džunglikasvatus ja loomulik pärilik intelligentsus, sellisena kehastab ta Ameerika mehelikku ideaali (Reid 
2017: 147-148). ${ }^{12}$ Tarzan on osav, õiglane ja julge, n-ö positiivsete iseloomujoontega, sobides poiste rollieeskujuks. Samuti ei kuulu ta mängijate „vahetusse eluringi”, kinnitades eespool toodud väidet selle kohta, et kujutlusmängude rollid võetakse meelsasti ka mujalt kui kodustest eeskujudest.

Tarzani filmi olevat imiteerinud just poisid. Tarzani moodi „liaanide küljes puultpuule hõljumist" ja tema huike kordamist mäletab küll naine, kuid mängijatena nimetab ta poisse (K. H., snd 1938). Kaks naist mäletavad, et nad mängisid Tarzanimängu koos poistega. Nagu eespool toodud meenutusest selgus, kaasati mängu ka üks tüdruk, kuid rollid jagati vastavalt filmistsenaariumile, tüdrukule usaldati Jane’i roll. Tarzani-mängu rollide sooline jaotus meenutab sõjamängude oma. Ka neis jäid tüdrukutele sageli teisejärgulised rollid. Mängusüžee nägi ette, et peamistes osades on poisid. Samamoodi anti sõjamängudes, kus venelased võitlesid sakslastega, tüdrukutele vaenlase ehk sakslase osa, sest poisid ei tahtnud mängida kaotajaid (vt nt EKM ERA, DK 117, 5; EKM ERA, DK 481, 3 [28]). Kuna lapsed elavad oma rolli väga sisse, pole neil kerge mängida vaenlast või üldse negatiivset ja halbade omadustega tegelast. Negatiivne tegelane võib mängu lõpus ebaõnnestuda või surma saada. Mängus kujutletav tunne võib olla laste jaoks nii reaalne, et neil on raske seda imiteerida (Kalliala 2006: 79, 86-87).

Eelkooli- ja kooliealiste laste mängudes on poiste rollid traditsiooniliselt mehised ning nende staatus on kõrgem kui tüdrukute rollidel. Poisid ei esine kunagi kellegi eest hoolitseja osas, tõdeb Ulla Lipponen, vaadeldes haiglamängu 1989. aastal ühel Soome kooli mänguväljakul. Nii avaldub sooline ebavõrdsus laste mängude rollijaotuses (Lipponen 1999).

Kui paigutada Tarzan Nõukogude Liidu sõjajärgsesse olustikku, tõstatub olulisena joon, mis eriti selgelt eristab Tarzani tegelaskuju nõukogude filmikangelastest. Romantiline seiklusfilm andis lastele julge ja osava meeseeskuju, kes ei olnud vägivaldne ning kelle elu peamine eesmärk ei olnud võidelda vaenlase vastu. Neid mänge saab vaadelda kui laste fantaasiarikkaid rollimänge: reeglid improviseeritakse ja mängu kulg sõltub hetkeimpulsist. Sõjamängukangelastest ja üldisemalt sõjamängust erineb Tarzani-mäng selle poolest, et seal ei ole kahte võistlevat poolust, kes omavahel jõudu katsuvad. Film pakkus lastele mängimiseks uusi ideid, uue eksootilise temaatika - mees džunglist. Filmi menu laste hulgas tingis selle seikluslik ning muinasjutuline süžee, teistsugune maailm, mis sealt avanes.

\section{Filmidest inspiratsiooni saanud tüdrukute tegevused}

Kinos või teleris nähtud kaunite näitlejatega sarnaneda tahtmist ja nende järelemängimist saab vaadelda oma soolise identiteedi loomisena. Shirley Temple, Zarah Leander jt tolleaegsed näitlejad olid ajastu iluideaalid. Linda Dégh võrdleb tänapäeva filmitähti muinasjutukangelannadega. Nagu muinasjuttudes, tuuakse ka tänapäeva meedias nende Hollywoodi stiilis isiklik elu avalikkuse ette oma luksuse, ilu ja

${ }^{12}$ Loo autor Burroughs iseloomustab Tarzanit kui „mehelikkuse täiuslikku isendit”, Tarzani selline kujutamine oligi üks tema eesmärkidest (Reid 2017). 
romantikaga. See on kui „sädelev ja kauge unistustemaa tavalistele inimestele, keda ümbritseb igapäevane hall ja halastamatu tööstus-maailm”. (Dégh 2003: 43-44)13

Väga populaarne oli sel ajal tüdrukute hulgas pabernukkude meisterdamine, neile riiete joonistamine ja nendega mängimine. Ka seda on seotud filmi-, aga samuti teatrinäitlejate tegevuse ja elu kujutamisega. Ning nagu eespool toodud näidetest selgub, imiteerisid tüdrukud filmides nähtut oma mängudes.

Enese või oma nukkude kaunitesse rõivastesse riietamine, nende kujutamine ilusate ja kaunitena on omamoodi „luksuse ja ilusa elu illusiooni” loomine. Filmide ja filminäitlejate abil „müüakse” ja luuakse ka romantilist tunnet, tüdrukute romantiline kultuur on tugevalt seotud tarbimisega. Filmid (kui kaubad) kujundavad tüdrukute arusaama romantilistest tunnetes ja suhetest (Illouz 1997).

1950. aastatel said neiuks sirguvate tüdrukute unistused toitu välismaa armastusfilmidest. Nagu eespool öeldud, jõudsid kümnendi keskel Nõukogude kinodesse India muusikalised armastusfilmid ja Argentiina melodramaatilised filmid. ${ }^{14}$ Filmid mõjutasid tüdrukute seisukohti ja olid üheks eeskujuks romantilisele käitumisele. Kinoteemalistes kirjutustes meenutatakse, kuidas pärast India armastusfilmide vaatamist astuti tänavale nutumärja näoga - melodramaatiline film avaldas neidudele mõju (EKM EFA I 317, 16-17< Valga l < Kose khk - E. M., snd 1944 (2019)).

Tüdrukute kultuuri juurde kuuluvaks peetakse ka romantiliste teemade armastuse ja suhete - esilolekut. Seda, et filmides mõjutas neid kui tüdrukuid ja neide just armastusteema, nimetavad kirjutajad ise. Oma suurima filmielamusena „Husaariballaadi”15 meenutaja selgitab filmi mõjuvust: „Film oli värviline, armastusteemaline ja mängisid väga ilusad näitlejad. Eriti läks mu hinge koht, kus tütarlaps laulis, nukk süles. Selles laulus oli igatsus oma armsama järele. Teema ja tunne puudutasid mind sügavalt, sest endal oli selle tunde ootus, aga kogetud veel polnud." (EKM ERA, DK 630, 15-17 < Häädemeeste khk - M. J., snd 1952 (2019))

Nagu samuti eespool välja on toodud, kogusid tüdrukud näitlejate pilte oma albumitesse ning vahetasid neid omavahel. Tüdrukute XX sajandil populaarseks muutunud käsikirjaliste albumite, laulikute ja päevaraamatute laia levimise põhjuseks loetakse seda, et tüdrukud teostasid selle tegevuse abil oma täitumata soove, vastamata tundeid ning igatsusi. Tüdrukute subkultuuri uurimisel on sellist eneserepresentatsiooni peetud üheks olulisemaks ealise, isiku- ja rühmakäitumise tunnusjooneks. Vaadates tüdrukute armastusteemalisi lugusid, järeldab Eda Kalmre, et tüdrukutele on neis kirjalikes kogudes valdav armastuse ja sõpruse teemade käsitlemine oluline nende küpsemisel (Kalmre 2010, 2015b). Ka filminäitlejate fotode kogumine albumisse võis teenida sama eesmärki - olla oluliste teemade ülevalhoidja ajal, mil sirguti neiust naiseks. Olenemata ajast, keskkonnast ja kontekstist, määratlevad tüdrukud oma elu ja identiteeti romantilise kultuuri kaudu (Kalmre 2015a: 1340).

\footnotetext{
${ }^{13}$ Soostereotüüpidest muinasjuttudes vt Toomeos-Orglaan 2013.

${ }^{14}$ Legendaarseteks said India näitleja Raj Kapoor ja Argentiina näitlejanna Lolita Torres. LadinaAmeerika filmide kohta Nõukogude Liidus vt Rupprecht 2017.

${ }^{15}$ „Husaariballaad” (Mosfilm, 1962) on režissöör Eldar Rjazanovi muusikaline komöödia, peaosades Juri Jakovlev ja Larisa Golubkina. Tegevus toimub 1812. aastal.
} 
1950. aastatel said neiuks sirguvate tüdrukute unistused toitu välismaistest armastusfilmidest. Tüdrukute romantilist kultuuri püüti luua näitlejate fotosid kogudes ning filme mängudes jäljendades. See oli allikas, millele toetudes ehitati üles oma sooline identiteet ning arusaam mehe ja naiste rollidest, armastusest ja romantilistest suhetest.

\section{Kokkuvõte}

Sõjajärgses Eestis, nagu kogu Nõukogude Liidus, oli kino üks väheseid meelelahutuse võimalusi. Huvi kino vastu oli suur, kuna kino täitis enne televisiooni hilisstalinistlikul ajajärgul tähtsaimat rolli visuaalse meediumina, kuid oli ka omamoodi aken läände. Kassahittideks kujunesid pärast Teist maailmasõda linastunud trofeefilmid, mis erinesid Nõukogude filmidest nii teemade, kujutusviiside kui ka olustiku poolest. Luksuslik, särav ja uhke maailm vastandus 1950. aastate Nõukogude Eesti vaesele tegelikkusele, hirmudele ja ideoloogilisele surutisele, tekitades omamoodi kultuurišoki.

Tänu laialt levinud visuaalkultuurile - kinole - kujunesid välja ka sealt inspiratsiooni saanud laste mängud ja harrastused. Filmid pakkusid mängudesse ka tollasest tegelikkusest erinevaid teemasid (džungliseiklused, armastusteema, iluga seotud teemadering) ning teistsuguseid mehe- ja naiseideaale, aga laiemalt ka arusaamist romantilistest suhetest ja käitumisest. Trofeefilmidest inspireeritud laste tegevus oli mitmekesine, erinedes sooliselt ja vanuseliselt. Hästi joonistub välja see, kuidas lapsed kohandavad oma kultuuri nii täiskasvanute- kui ka lastekultuurist pärit ainest. Trofeefilmidest mõjutatud mänge ja harrastusi saab vaadata kui laste viisi luua endale mängumaailm, mis erineks päriselust ning viiks neid unistuste- ja fantaasiamaailma. Küllap aitasid need lastena kogetud eredad positiivsed emotsioonid tervel sõjajärgsel põlvkonnal säilitada unistust vabast ja ilusamast maailmast, kui seda oli Nõukogude Liit.

Artikli valmimist on toetanud Eesti Haridus- ja Teadusministeeriumi uurimisprojekt EKKD65 „Kuidas allikatest saab kultuur: eesti aines Eesti Kirjandusmuuseumi kogudes ja andmebaasides" ja Euroopa Liit Euroopa Regionaalarengu Fondi kaudu (Eesti-uuringute Tippkeskus).

\section{ARHIIVIALLIKAD}

Eesti Kirjandusmuuseumi (EKM) Eesti Kultuurilooline Arhiiv (EKLA)

f 350, m 1: 2679 (2016/2017)

\section{Eesti Kirjandusmuuseumi (EKM) Eesti Rahvaluule Arhiiv (ERA)}

EFA - Eesti folklooriarhiivi rahvaluulekogu

ERA, DK - Eesti Rahvaluule Arhiivi digikäsikirjad

ERA - Eesti Rahvaluule Arhiivi rahvaluulekogu 


\section{KIRJANDUS}

Bauman, Richard; Briggs, Charles L. 1990. Poetics and performance as critical perspectives on language and social life. - Annual Review of Anthropology, kd 19, lk 59-88.

Borissov 2002 = Sergej Borisov, Mir russkogo devičestva. 70-90 gody XX veka. Moskva: Naučno-izdatel'skij centr „Ladomir”. [Сергей Борисов, Мир русского девичества. 70-90 годы ХХ века. Москва: Научно-издательский центр „Ладомир”.]

Borissova 2008 = Natalija Borisova, Ljublju - i ničego bol'še. Sovetskaja ljubov' 1960-1980-h godov. - SSSR: Territorija ljubvi. (Novye materialy i issledovanija po istorii russkoj kul'tury 6.) Moskva: Novoe izdatel'stvo, lk 40-59. [Наталия Борисова, Люблю - и ничего больше. Советская любовь 1960-1980-х годов. - СССР: Территория любви. (Новые материалы и исследования по истории русской культуры 6.) Москва: Новое издательство.]

Chudacoff, Howard P. 2007. Children at Play. An American History. New York: New York University Press.

Corsaro, William A. 2005. The Sociology of Childhood. Thousand Oaks [etc.]: Pine Forge Press.

Dégh, Linda 2003. Ilu, jõukus ja võim. Naiste karjäärivõimalused rahvajuttudes, muinasjuttudes ja tänapäeva meedias. - Mäetagused, nr 23, lk 9-55.

ENE 1975 = Eesti nõukogude entsüklopeedia. 7. kd. rund-ting. Tallinn: Valgus.

Evaldsson, Ann-Carita 2009. Play and games. - The Palgrave Handbook of Childhood Studies. Basingstoke-New York: Palgrave Macmillan, lk 316-331.

Fjodorov jt 2017 = A. V. Fedorov, A. A. Levickaja, O. I. Gorbatkova, Škola i vuz v zerkale audiovizual'nyh mediatekstov. Osnovnye podhody k probleme issledovanija. - Mediaobrazovanie. Media Education, nr 2, lk 188-206. [А. В .Федоров, А. А. Левицкая, О. И. Горбаткова, Школа и вуз в зеркале аудиовизуальных медиатекстов: основные подходы к проблеме исследования. - Медиаобразование, no. 2.] https://cyberleninka. $\mathrm{ru} /$ article/n/shkola-i-vuz-v-zerkale-audiovizualnyh-mediatekstov-osnovnye-podhodyk-probleme-issledovaniya (4. I 2020).

Hughes, Linda A. 1993. „You Have to Do It with Style.” Girls' games and girls' gaming. - Feminist Theory and the Study of Folklore. Urbana-Chicago: University of Illinois Press, lk 130-165.

Illouz, Eva 1997. Consuming the Romantic Utopia. Love and the Cultural Contradictions of Capitalism. Berkeley-Los Angeles-Oxford: University of California Press.

Jaago, Tiiu 2018. Elulugu folkloristlikust vaatepunktist. - Mäetagused, nr 71, lk 5-22.

Kalliala, Marjatta 2006. Play Culture in a Changing World. Maidenhead: Open University Press.

Kalmre, Eda 2010. Tüdrukute materjalikogudest ja eneseesitlusest Internetis rate.ee päevikute armastusjuttude näitel. - Tulnukad ja internetilapsed. Uurimusi laste- ja noortekultuurist. (Tänapäeva folkloorist 8.) Toim E. Kalmre. Tartu: EKM Teaduskirjastus, lk 214-245.

Kalmre, Eda 2015a. Tüdrukute omaloomingulised armastusjutud - romantika, ideaalid, eeskujud ja arengud. - Looming, nr 9, lk 1327-1341.

Kalmre, Eda 2015b. Self-created love stories in girls' romantic culture. History and evolution. - Rethinking Romantic Love. Discussions, Imaginaries and Practices. Cambridge: Cambridge Scholars Publishing, lk 241-270. 
Kannike, Anu; Vahtre, Lauri 2018. Eesti eluolu 100 aastat. Petrooleumilambist nutitelefonini. Tallinn: Post Factum.

Kanter, Kadri 2014. Eesti NSV kinematograafia ministeerium 1946-1953. Eellugu, tegevuse põhisuunad ja likvideerimine. Magistritöö eesti ajaloo õppetoolis. Tartu: Tartu Ülikool.

Kenez, Peter 2009. Cinema and Soviet Society. From the Revolution to the Death of Stalin. London-New York: IB Tauris.

Kirss, Tiina Ann; Hinrikus, Rutt 2010. Elust elulooks. Kuidas kirjutada elulugu - näiteid ja näpunäiteid. Eesti Kirjandusmuuseum, ühendus Eesti Elulood. Tallinn: Tänapäev.

Korkiakangas, Pirjo 1996. Mängud ja mänguasjad kultuuri ja elukeskkonna kajastajaina. Mängult-päriselt. (Tänapäeva folkloorist 2.) Toim Mare Kõiva. Tartu: Eesti Rahvaluule Arhiiv, Eesti Keele Instituut, lk 66-78.

Kõresaar, Ene 2005. Elu ideoloogiad. Kollektiivne mälu ja autobiograafiline minevikutõlgendus eestlaste elulugudes. (Eesti Rahva Muuseumi sari 6.) Tartu: Eesti Rahva Muuseum.

Lindstrom, Martin; Seybold, Patricia B. 2004. Bränd ja lapsed. Särav pilguheit tänaste laste mõttemaailma ja nende suhetesse brändidega. Tlk Liina Loko. Tallinn: Noman.

Lipponen, Ulla 1999. Haigla-rollimäng - tähelepanekuid tüdrukute ja poiste ühismängu kujunemise kohta. - Kuuldust-nähtust. (Tänapäeva folkloorist 4.) Toim Eda Kalmre. Tartu: Eesti Kirjandusmuuseum, lk 146-166.

Marsh, Jackie; Plowman, Lydia; Yamada-Rice, Dylan; Bishop, Julia; Lahmar, Jamal; Scott, Fiona 2018. Play and creativity in young children's use of apps. - British Journal of Educational Technology, kd 49, nr 5, lk 870-882.

Mertelsmann, Olaf 2011. Trophy films and western radio broadcasting as a window to the world in post-war Estonia. - Central and Eastern European Media under Dictatorial Rule and in the Early Cold War. (Tartu Historical Studies 1.) Frankfurt am Main: Peter Lang Verlag, lk 61-74.

Mertelsmann, Olaf 2012. Everyday Life in Stalinist Estonia. (Tartu Historical Studies 2.) Frankfurt am Main: Peter Lang Verlag.

Moshenska, Gabriel 2019. Material Cultures of Childhood in Second World War Britain. London: Routledge.

Opie, lona; Opie, Peter 1984. Children's Games in Street and Playground. Oxford-New York: Oxford University Press.

Pajur, Ago; Tannberg, Tõnu (toim) 2005. Eesti ajalugu VI. Vabadussõjast taasiseseisvumiseni. Tartu: Ilmamaa.

Paksuniemi, Merja; Mättä, Kaarina; Uusiautti, Satu 2015. Childhood in the shadow of war: filled with work and play. - Children's Geographies, kd 13, nr 1, lk 114-127.

Portelli, Alessandro 2006. Mitä tekee muistitietotutkimuksesta erityisen? - Muistitiedotutkimus. Metodologisia kysymyksiä. (Tietolipas 214.) Helsinki: Suomalaisen Kirjallisuuden Seura, lk 49-66.

Pöysä, Jyrki 2009. Kogumisvõistlused pärimusliku ajaloo uurimises. Tlk Kadri Jaanits. Mäetagused, nr 43, lk 39-60.

Raudsepp, Anu; Veski, Karin 2015. Vaenlase ja kangelase kuvandid sõjajärgse stalinismi aegsetes eestikeelsetes originaalõpikutes. - Nõukogude Eesti külma sõja ajal. (Eesti Ajalooarhiivi Toimetised 23 (30).) Tartu: Eesti Ajalooarhiiv, lk 200-217. 
Reid, Conor 2017. „This Savage World Was an Open Book.” Genre and landscape in Edgar Rice Burroughs's Tarzan series. - Popular Culture, kd 50, nr 1, lk 147-162.

Rupprecht, Tobias 2017. Soviet Internationalism after Stalin. Interaction and Exchange Between the USSR and Latin America During the Cold War. Cambridge: Cambridge University Press.

Rõblova, Nazarova 2014 = Marina Ryblova, Marina Nazarova, „Igrajut mal'čiki v vojnu”: Igra kak sposob osvoenija det'mi prostranstva vojny. - Vestnik Volgogradskogo gosudarstvennogo universiteta. Serija 4. Istorija. Regionovedenie. Meždunarodnye otnošenija. Volgograd, lk 105-115. [Марина Рыблова, Марина Назарова, „Играют мальчики в войну”. Игра как способ освоения детьми пространства войны. - Вестник Волгоградского государственного университета. Серия 4. История. Регионоведение. Международные отношения. Волгоград.]

Shuffelton, Amy 2009. Fantasy play. - Encyclopedia of Play in Today's Society, kd 1. Thousand Oaks: SAGE Publishing, Rudgers University, lk 223-227.

Siibak, Andra; Vinter, Kristi 2014. „Ma tahaks olla Pommimees!” - lasteaialaste meedialemmikute analüüs ja nende võimalik kasutamine väärtuskasvatuses ja sootundlikus lasteaias. - Ariadne Lõng, nr 1-2, lk 85-100.

Sutton-Smith, Brian 1981. A History of Children's Play. The New Zealand Playground, 18401950. Philadelphia: University of Pennsylvania Press.

Süss, Daniel 2007. Socialization and Media. - Encyclopedia of Children, Adolescents, and the Media. Thousand Oaks: SAGE Publishing, lk 782-784.

Tanis, Kristina 2017. Trofejnoe kino v SSSR v 1940-1950-e gg. K istorii formirovanija fenomena. - Kul'tura i iskusstvo, nr 12, lk 85-91. [Танис Кристина, Трофейное кино в СССР в 1940-1950-е гг. К истории формирования феномена. - Культура и искусство, но. 12.]

Toomeos-Orglaan, Kärri 2013. Gender stereotypes in Cinderella (ATU 510A) and the princess on the Glass Mountain (ATU 530). - Journal of Ethnology and Folkloristics, kd 7, nr 2, lk 49-64.

Tucker, Elizabeth 2008. Children's Folklore. A Handbook. Westport (Connecticut): Greenwood Press.

Tuisk, Astrid 2018. Sõjamoonaga mängimine Eestis Teise maailmasõja ajal ja pärast seda: folkloristlik vaatenurk. - Mäetagused, nr 71, lk 175-196.

Tuisk, Astrid 2019. Meenutused nukkudest ja nendega mängimisest 1940.-1950. aastate Eestis. - Mäetagused, nr 74, lk 51-76.

Tungal, Leelo 2008. Seltsimees laps ja suured inimesed. Veel üks jutustus õnnelikust lapsepõlvest. Tallinn: Tänapäev.

Veidenbaum, Kristina 2003. Tahan saada Teletupsuks! Televisiooni mõjust lasteaialaste loovmängudele. - Teekond. (Pro Folkloristica X.) Tartu: Eesti Kirjandusmuuseum, lk 197-209.

Virtanen, Leea 1974. Children’s Lore. Helsinki: Suomalaisen Kirjallisuuden Seura.

Vissel, Anu 2004. Meedia kui mängude vahendaja ja uute mängude allikas. Lastepärimus muutuvas ühiskonnas. - Ars Musicae Popularis, nr 15. Tartu: Eesti Kirjandusmuuseumi etnomusikoloogia osakond, lk 179-205. 
Willett, Rebekah 2014. Remixing children's cultures. Media-referenced play on the playground. - Children's Games in the New Media Age. Burlington: Routledge, lk 133-151.

Astrid Tuisk (snd 1968), MA, Eesti Kirjandusmuuseumi Eesti Rahvaluule Arhiivi teadur (Vanemuise 42, 51003 Tartu); Tartu Ülikooli kultuuriteaduste instituudi doktorant, astrid.tuisk@folklore.ee

\section{Film-inspired games of children and youth remembered to have been played in Estonia in the 1950s}

Keywords: children's games, children's culture, post-war period, Soviet cinema, Stalinist Estonia, trophy films.

The article discusses the media-inspired games played by Estonian children in the 1950s. The source material comes from the relevant essays sent to the competition of collecting children's games, which was organized by the Estonian Folklore Archives at the Estonian Literary Museum. Besides describing their childhood activities the contributors had managed to explain, discuss and contextualize the games. Also, some essays on the topic "Cinema in my life" by the participants of the biography writing group were used. The authors of the essays, having chosen a child's point of view, refrained from explaining the historical and political conditions of the time. So the social and cultural context is provided by the article.

In post-war Estonia, like in the whole Soviet Union, cinema was one of the few options for entertainment. In the late Stalinist period it was an important visual medium, also serving as a "window to the West". After World War II Stalin's (foreign) trophy films became real blockbusters. The world appearing on the screen differed from the surrounding inferior reality to the extent of producing a cultural shock. It also differed from the experience of Soviet war films.

The cinema inspired various games and activities. Most topics (jungle adventures, love) as well as the male and female ideals offered by the films differed by far from the everyday. Even half a century later the impressions are still vivid.

Our analysis of the film-inspired activities demonstrates how creatively children can use and adapt elements of adult culture, thus creating their own unique culture.

The children's games and activities inspired by the trophy films can be seen as children's way of creating their own playworld differing from real life and taking them to the realm of dreams and fantasy. Those bright positive emotions experienced at an early age must have helped a whole post-war generation to nurture a dream of a more free and beautiful world than the Soviet everyday.

Astrid Tuisk (b. 1968), MA, Estonian Literary Museum, Estonian Folklore Archives, Researcher (Vanemuise 42, 51003 Tartu); University of Tartu, Institute of Cultural Studies doctoral student, astrid.tuisk@folklore.ee 